University of Wollongong

Research Online

Australian Institute for Innovative Materials -

Papers

Australian Institute for Innovative Materials

$1-1-2014$

Na3V2(PO4)3 particles partly embedded in carbon nanofibers with superb kinetics for ultra-high power sodium ion batteries

Junghoon Yang

Dongguk University

Dongwook Han

Korea Advanced Institute of Science and Technology

Mi Ru Jo

Dongguk University

Kyeongse Song

Dongguk University

Yongil Kim

University of Glasgow

See next page for additional authors

Follow this and additional works at: https://ro.uow.edu.au/aiimpapers

Part of the Engineering Commons, and the Physical Sciences and Mathematics Commons

Research Online is the open access institutional repository for the University of Wollongong. For further information contact the UOW Library: research-pubs@uow.edu.au 


\title{
Na3V2(PO4)3 particles partly embedded in carbon nanofibers with superb kinetics for ultra-high power sodium ion batteries
}

\begin{abstract}
We here describe the extraordinary performance of NASICON Na $3 V_{2}\left(\mathrm{PO}_{4}\right)_{3}$-carbon nanofiber (NVP-CNF) composites with ultra-high power and excellent cycling performance. NVP-CNFs are composed of CNFs at the center part and partly embedded NVP nanoparticles in the shell. We first report this unique morphology of NVP-CNFs for the electrode material of secondary batteries as well as for general energy conversion materials. Our NVP-CNFs show not only a high discharge capacity of approx. $88.9 \mathrm{~mA} \mathrm{~h} \mathrm{~g}^{-1}$ even at a high current density of $50 \mathrm{C}$ but also approx. 93\% cyclic retention property after 300 cycles at 1 C. The superb kinetics and excellent cycling performance of the NVP-CNFs are attributed to the facile migration of $\mathrm{Na}$ ions through the partly exposed regions of NVP nanoparticles that are directly in contact with an electrolyte as well as the fast electron transfer along the conducting CNF pathways.
\end{abstract}

\section{Keywords}

ultra, kinetics, superb, nanofibers, carbon, embedded, partly, high, particles, batteries, 3, po4, na3v2, power, sodium, ion

Disciplines

Engineering | Physical Sciences and Mathematics

\section{Publication Details}

Yang, J., Han, D., Jo, M. Ru., Song, K., Kim, Y., Chou, S., Liu, H. \& Kang, Y. (2014). Na3V2(P04)3 particles partly embedded in carbon nanofibers with superb kinetics for ultra-high power sodium ion batteries. Journal of Materials Chemistry A, 3 (3), 1005-1009.

\section{Authors}

Junghoon Yang, Dongwook Han, Mi Ru Jo, Kyeongse Song, Yongil Kim, Shulei Chou, Hua-Kun Liu, and Yong-Mook Kang 


\section{$\mathrm{Na}_{3} \mathrm{~V}_{2}\left(\mathrm{PO}_{4}\right)_{3}$ Particles Partly Embedded in Carbon}

\section{Nanofibers with Superb Kinetics for Ultra-High Power Sodium Ion Batteries}

Junghoon Yang, ${ }^{\dagger}$ Dong-Wook Han, ${ }^{\S}$ Mi Ru Jo, ${ }^{\dagger}$ Kyeongse Song, ${ }^{\dagger}$ Yong-Il Kim, ${ }^{\#}$ Shu-Lei Chou, $\neq$ Hua-Kun Liu, $\neq$ Yong-Mook Kang ${ }^{\dagger, *}$

* Corresponding authors: dake1234@dongguk.edu

${ }^{\dagger}$ Department of Energy and Materials Engineering, Dongguk University-Seoul, Seoul 100-715, Republic of Korea, ${ }^{\S}$ Department of Materials Science and Engineering Korea Advanced Institute of Science and Technology Yuseong, Daejeon, 305-340, Republic of Korea, ${ }^{\#}$ Korea Research Institute of Standards and Science (KRISS), Daejeon 305-340, Republic of Korea, ¥Institute for Superconducting and Electronic Materials, Australian Institute for Innovative Materials, University of Wollongong, Innovation Campus, North Wollongong, NSW, Australia

KEYWORDS: Sodium ion battery, NASICON, $\mathrm{Na}_{3} \mathrm{~V}_{2}\left(\mathrm{PO}_{4}\right)_{3}$, Carbon nanofiber, Composite 


\begin{abstract}
We here describe a novel structure of $\mathrm{Na}_{3} \mathrm{~V}_{2}\left(\mathrm{PO}_{4}\right)_{3}$-carbon nanofibers (NVP-CNF) composites with ultra-high power and excellent cycling performance. NVP-CNFs are composed of CNFs at the center part and partly embedded NVP nanoparticles in the shell. We first report this unique morphology of NVP-CNFs for the electrode material of secondary batteries as well as general energy conversion materials. Our NVP-CNFs show not only a high discharge capacity of $\sim 88.9$ mAh $\mathrm{g}^{-1}$ even at a high current density of $50 \mathrm{C}$ but also $93 \%$ cyclic retention property after 300 cycles at 1C. The superb kinetics and excellent cycling performance of the NVP-CNFs are attributed to the facile migration of Na ions through the partly exposed regions of NVP nanoparticles that directly contact with an electrolyte as well as the fast electron transfer along the conducting CNF pathways.
\end{abstract}


Rapid advancements in renewable energy sources—including solar, wind, water, etc.—have encouraged the development of reliable energy storage systems (ESSs). ${ }^{1,2}$ Up to now, lithium ion batteries (LIBs) have been considered as one of the most attractive ESSs owing to their high energy/power densities and stable cycling performance. However, the growing concern about the exhaustion of lithium resources and the subsequent increase in their cost have restricted the application of LIBs to large-scale power sources including ESSs. ${ }^{3,4}$ On the contrary, Na ion batteries (NIBs) are a leading candidate for new energy storage and powering systems necessary for large appliances because of the higher abundance of Na resources (Na is the fourth most abundant element in the earth's crust), their environmental benignity, and their similar intercalation chemistry to LIBs. ${ }^{5,6}$ However, the low ionic mobility of Na in the crystal structure of cathode materials for NIBs, induced by the larger ionic radius of Na compared with lithium, has limited the practical application of NIBs. In this regard, the development of highperformance cathode materials for NIBs should be considered as a priority for the commercialization of NIBs. Various cathode materials (e.g., $\mathrm{Na}_{\mathrm{x}} \mathrm{CoO}_{2},{ }^{7} \mathrm{Na}_{0.44} \mathrm{MnO}_{2},{ }^{8,9}$ $\mathrm{NaFePO} 4,{ }^{10} \mathrm{NaMn}_{1 / 2} \mathrm{Fe}_{1 / 2} \mathrm{PO}_{4},{ }^{11}$ and $\left.\mathrm{Na}_{4} \mathrm{Fe}(\mathrm{CN})_{6} / \mathrm{C}^{12}\right)$ have been reported, but they have suffered from low power densities and poor long-term cycling performance. In spite of these drawbacks, the interest in the cathode materials with 3-D open frameworks has increased owing to their large interstitial sites for accommodating Na ions during cycling. ${ }^{13}$

$\mathrm{Na}_{3} \mathrm{M}_{2}\left(\mathrm{XO}_{4}\right)_{3}$ with a Na super ionic conductor (NASICON) framework is a typical example of an open-structured cathode material for NIBs. ${ }^{14}$ In particular, Na vanadium phosphate, $\mathrm{Na}_{3} \mathrm{~V}_{2}\left(\mathrm{PO}_{4}\right)_{3}(\mathrm{NVP})$, has attracted great attention thanks to its inherently high ionic conductivity and high operating voltage $\left(\sim 3.4 \mathrm{~V}\right.$ vs. $\left.\mathrm{Na}^{+} / \mathrm{Na}\right)$ that corresponds to $\mathrm{V}^{4+} / \mathrm{V}^{3+}$ redox couples. According to previous reports, however, the poor electronic conductivity and large particle size 
of NVP tend to lower its electrochemical performance. ${ }^{15,16}$ Hence, a new strategy is required to realize ultra-high power NVP by enhancing its electronic conductivity and shortening the diffusion length of $\mathrm{Na}$ ions inside it.

One of the most common and effective ways to improve the electronic conductivity of NASICON-structured cathode materials is to coat the conductive carbon layers on the surfaces of these materials. ${ }^{17-21}$ However, the migration of Na ions through interfaces between cathode materials and electrolyte could be hindered by the thick and uniform carbon layers. ${ }^{22,23}$ This double-sideness of carbon coating made us consider another structure for NVP-carbon composites. We have noticed that the structural characteristics of anode material-1D carbon composites based on carbon nanotube (CNT) and so on significantly contributed to their excellent electrochemical performances. Actually, the nano-sized anode materials well grown on the surface of CNT demonstrated greatly improved kinetic properties. ${ }^{24}$ So, in the viewpoint of high electron conduction and facile Na ion transport, this structure looks clearly fascinating when it is adopted for the electrode material of LIBs or NIBs. Because this structure has been made primarily through precipitation until now, it has been rarely reported for the cathode materials of LIBs or NIBs.

Here, toward facile Na ion migration and rapid electronic conduction, we report on a distinctive composite structure in which NVP nanoparticles are partly embedded in carbon nanofibers (NVP-CNF). The opposite side of partly embedded NVP nanoparticles was directly exposed to an electrolyte. This unique morphology of NVP-CNF not only provides fast electron transfer channels along the CNF but also enables Na ions to readily come from the electrolyte through the regions of NVP exposed to the electrolyte. In addition, the short diffusion length of Na ions in the NVP nanoparticles can make a positive effect on the kinetics of NVP-CNF. 
Resultantly, the CNF-induced high electronic transfer and facile Na ion migration through the partly embedded NVP particles enabled an impressive improvement in the electrochemical properties (capacity, rate capability, and cycling performance) of NVP-CNF cathode materials. NVP-CNF was prepared by electrospinning method followed by thermal treatment. Here, we could make a difference in its final morphology by changing the calcination time from 4h (NVPCNF-4h) and to 6h (NVP-CNF-6h). 


\section{RESULTS AND DISCUSSION}

The X-ray diffraction (XRD) patterns of the synthesized NVP-CNF composites are shown in Figure 1(a). All the diffraction peaks of NVP-CNF were well matched to the reference pattern for NVP with the rhombohedral R-3c space group. ${ }^{14,25}$ The crystal structure of NVP is depicted in Figure 1(b). The $\mathrm{VO}_{6}$ octahedron links via corners sharing with tetrahedral $\mathrm{PO}_{4}$ units, which leads to the $3 \mathrm{D}\left[\mathrm{V}_{2}\left(\mathrm{PO}_{4}\right)_{3}\right]^{3-}$ framework. Na ions are occupied in two different sites having different oxygen environments: $\mathrm{Na}(1)$ and $\mathrm{Na}(2)$ interstitial sites with six- and eight-fold

coordination, respectively. ${ }^{26}$ As reported by Weixin's group, the $\mathrm{Na}(2)$ sites are relatively weakly connected to surrounding oxygen atoms when compared with $\mathrm{Na}(1)$ sites. Thus, the $\mathrm{Na}$ ions located in $\mathrm{Na}(2)$ sites are primarily involved in the electrochemical properties of NVP. ${ }^{27}$ The stable and large $\mathrm{Na}(2)$ sites formed in the crystal structure of NVP suppress the stress/strain that occurs when Na ions are diffused into/out of NVP crystals.

Figure 2 demonstrates the morphological characteristics of the NVP-CNF-6h investigated by electron microscopy. The field emission scanning electron microscope (FE-SEM) image of the NVP-CNF-6h showed a uniform distribution of NVP-CNF nanofibers (Figures 2a and S1). Moreover, from the transmission electron microscope (TEM) images shown in Figures 2b and 2c, we found that the CNF networks constructed the main stream of NVP-CNF composites, and NVP nanoparticles (50-200 nm in diameter) were irregularly dangled onto the CNF stem. The high-resolution TEM (HRTEM) image of the NVP-CNF exhibited a distinct lattice fringe, indicative of single crystalline NVP (Figure 2d). The width of $6.19 \AA$ between neighboring lattice fringes corresponds to ( $\left(\begin{array}{lll}0 & 1\end{array}\right)$ planes of NVP, while no periodic atomic arrangements were observed in CNF regions in the HRTEM image. However, the Raman spectroscopy of the NVP-CNF shown in Figure S2(a) revealed that the CNFs were comprised of crystalline carbon 
(G-band) and disordered carbon (D-band). ${ }^{28}$ Specific signals for NVP were also observed in the Raman spectra. ${ }^{29}$ The amount of carbon in the NVP-CNF was $~ 8.34 \mathrm{wt} \%$, as indicated by thermogravimetric analysis (Figure S2(b)). Herein, no carbon was found on the surfaces of NVP nanoparticles that were exposed to an electrolyte. Instead, NVP nanoparticles were partly embedded in the CNF networks (Figures 2c and 2d). Considering that a thick/dense carbon coating layer might hinder Na ion migration between the active material and an electrolyte, the unique morphology of our NVP-CNF can maximize the ionic conductivity without sacrificing its electronic conductivity by partial adhesion between NVP nanoparticles and CNFs.

Figure 3a presents the schematic diagram for the formation process of the NVP-CNF composite, which was clearly arranged by comparing the morphological difference between NVP-CNF-4h and NVP-CNF-6h. Figure S3 shows the representative TEM images of NVPCNF-4h. Unlike NVP-CNF-6h (Figure 2), NVP-CNF-4h contained smooth nanofiber surface with little roughness. The morphological change of NVP-CNF depending on heating time demonstrated how the unique morphology NVP-CNF-6h was formed with a simple electrospinning route. At the initial stage for calcination, Figure 3b indicates that the outer thick layer with $\sim 65 \mathrm{~nm}$ thickness is composed of NVP crystals that include $\sim 6 \mathrm{~nm}$ carbon coating layer on its surface. Meanwhile, the inner part corresponding to the core of this composite nanofiber mostly consists of a carbon layer with $\sim 50 \mathrm{~nm}$ thickness. Even if most of composite nanofibers had the above-mentioned structural characteristics after 4h calcination, some of them have already shown not only NVP layer agglomeration but also the following formation of uneven surface. This uneven distribution of NVP and carbon observed at NVP-CNF-4h was confirmed by energy dispersive X-ray spectroscopy (EDS) line scanning results given in Figure S4. This clearly proves that NVP-CNF starts to form NVP crystal and thereby the morphological 
feature of our final NVP-CNF composites somewhat appears around 4h calcination (Figure 3c). Finally, the outer NVP region completely changed into the spherical NVP particles partly embedded in the inner CNF as a result of a phase separation after $6 \mathrm{~h}$ heat treatment, and thereafter the advantageous structural feature of NVP-CNF for facile Na ion migration as well as fast electron conduction has been completed as shown in Figure 3d.

The electrochemical properties of the NVP-CNF composites are shown in Figure 4, which were measured in a voltage range of $2.7-4.0 \mathrm{~V}$ vs. $\mathrm{Na}^{+} / \mathrm{Na}$. The galvanostatic ( $0.1 \mathrm{C}$-rate) voltage profiles of the NVP-CNF-4h and NVP-CNF-6h featured a voltage plateau at $\sim 3.4 \mathrm{~V}$ that corresponded to a $\mathrm{V}^{4+} / \mathrm{V}^{3+}$ redox reaction. (Figure 4a). In this voltage plateau region, the material undergoes two-phase reaction between $\mathrm{Na}_{3} \mathrm{~V}_{2}\left(\mathrm{PO}_{4}\right)_{3}$ and $\mathrm{Na}_{1} \mathrm{~V}_{2}\left(\mathrm{PO}_{4}\right)_{3}$ (Figure S5). ${ }^{30}$ Resultantly, NVP-CNF-6h showed much better electrochemical performance than NVP-CNF-4h in terms of initial discharge capacity, rate capability, and long-term cycling performance. The initial discharge capacity of NVP-CNF-6h was $\sim 112.5 \mathrm{mAh} \mathrm{g}^{-1}$ at $0.1 \mathrm{C}$-rate, quite comparable to the theoretical capacity (117.6 $\mathrm{mAh} \mathrm{g}^{-1}$ ) of NVP. In particular, the maintenance of high capacity ( $\sim 88.9 \mathrm{mAh} \mathrm{g}^{-1}$ ) of NVP-CNF-6h even at an extremely high current density of 50 C-rate should be noted and emphasized, which coincided with $\sim 79 \%$ of its initial capacity measured at $0.1 \mathrm{C}$ rate (Figure $4 \mathrm{~b}$ ). In contrast, the discharge capacity of NVP-CNF-4h rapidly decreased as a function of the applied current density; it dropped to less than $20 \mathrm{mAh} \mathrm{g}^{-1}$ at a current density of 30 C-rate. Here, we can suggest that the superior rate capability of NVP-CNF-6h to NVP-CNF4h is mainly attributable to the unique morphology of the NVP-CNF-6h, as previously discussed in Figures 2 and 3. As observed in Figure 4c, NVP-CNF-6h maintained 93\% of its initial discharge capacity cycled at $1 \mathrm{C}$ even after 300 cycles. On the other hand, NVP-CNF-4h showed 78\% retention of its initial capacity just after 100 cycles (see inset of Figure 4c). This stable 
cycling performance of NVP-CNF-6h is very remarkable, because most of cathode materials for NIBs undergo serious capacity decay during cycling. Further evidence for the enhancement in kinetic properties of NVP-CNF-6h was provided by the galvanostatic intermittent titration technique (GITT) curves of NVP-CNF (Figure S6). The diffusion resistance of NVP-CNF could be estimated from the difference between the open circuit voltage (OCV) and the constant current voltage (CCV) obtained from GITT results. Resistance is known to be correlated with voltage polarization by Ohm's law $(\mathrm{R}=\Delta \mathrm{V} / \mathrm{I})$. Herein, we excluded the voltage polarization linked to IR-drop resistances that related to internal resistance of the material (Figure. S6) only to measure the change of diffusion resistance. The calculated diffusion resistances in figure 4(d) clearly demonstrates the kinetic difference between NVP-CNF-4h and NVP-CNF-6h. In the initial stage of charge reaction, NVP-CNF-4h looks like having a serious difficulty to extract $\mathrm{Na}$ ions from NVP structures. Actually, the calculated diffusion resistance of NVP-CNF-4h was three times higher than that of NVP-CNF-6h. Even though both samples showed similar diffusion behaviors during $\mathrm{V}^{4+} / \mathrm{V}^{3+}$ redox reaction, NVP-CNF-4h went through eight times higher diffusion resistance compared to NVP-CNF-6h to extract two formula units of Na ions completely in the last stage of charge reaction. The kinetic superiority of NVP-CNF-6h was also verified when Na ions re-inserted into NVP structure. Na ions easily migrated into not only NVP-CNF-4h but also NVP-CNF-6h in the initial stage of discharge. However, NVP-CNF-4h eventually underwent a sudden surge of diffusion resistance in the last stage of discharge reaction. Figure S7 proves that NVP-CNF-6h is much superior to NVP-CNF-4h also in terms of electronic conductivity. Hence, we believe that the improved electrochemical performance of NVP-CNF-6h can result from the facile migration of Na ions through its unique structure that 
NVP nanoparticles are partly embedded into CNFs and fast electron supply along CNFs toward NVP nanoparticles.

\section{Conclusions}

In conclusion, we succeeded in realizing NVP-CNF composites with ultra-high power and excellent cycling performance by electrospinning process followed by the regulated heat treatment. The NVP-CNFs were comprised of CNFs at the center of the NVP-CNFs and partially embedded NVP nanoparticles onto the CNFs. In this characteristic morphology of NVP-CNFs, while CNFs acted as a backbone for providing electronic conducting pathways toward the partially embedded NVP nanoparticles, the opposite NVP region that were exposed to and directly contacted with an electrolyte improved the ionic conductivity of Na ions into/out of NVP nanocrystals. Thus, this unique shape of NVP-CNF exhibited extraordinary electrochemical performances, which have been unprecedented to date for the cathode materials of NIBs. Our NVP-CNF not only showed a high discharge capacity even at high current density of 50 C-rate but also maintained $~ 93 \%$ of its initial discharge capacity (1 C-rate) even after 300 cycles. 


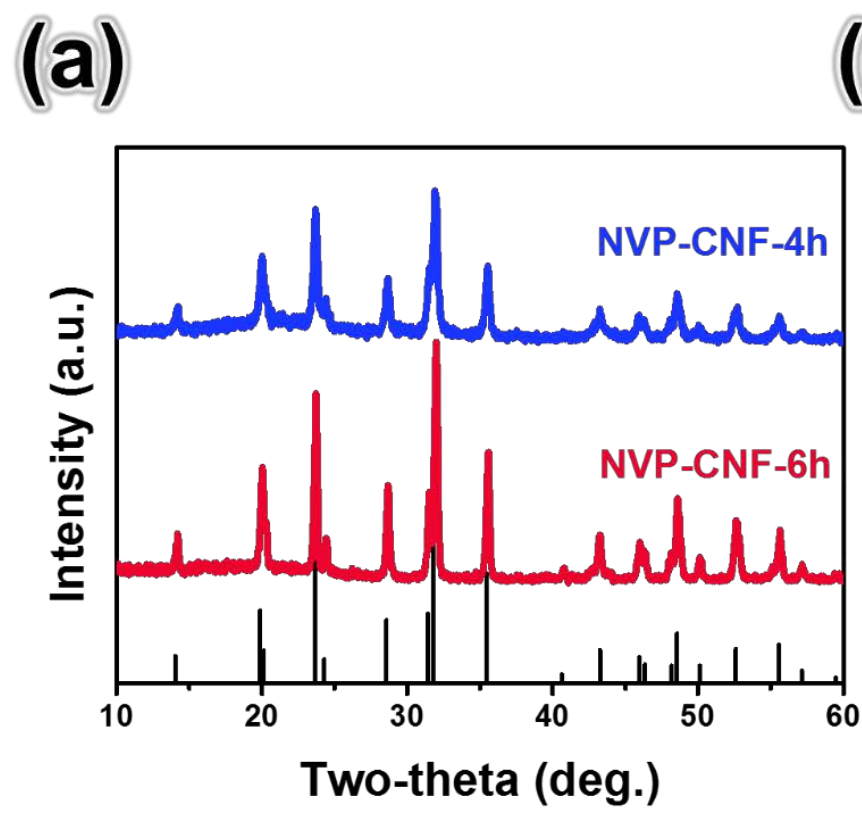

(b)

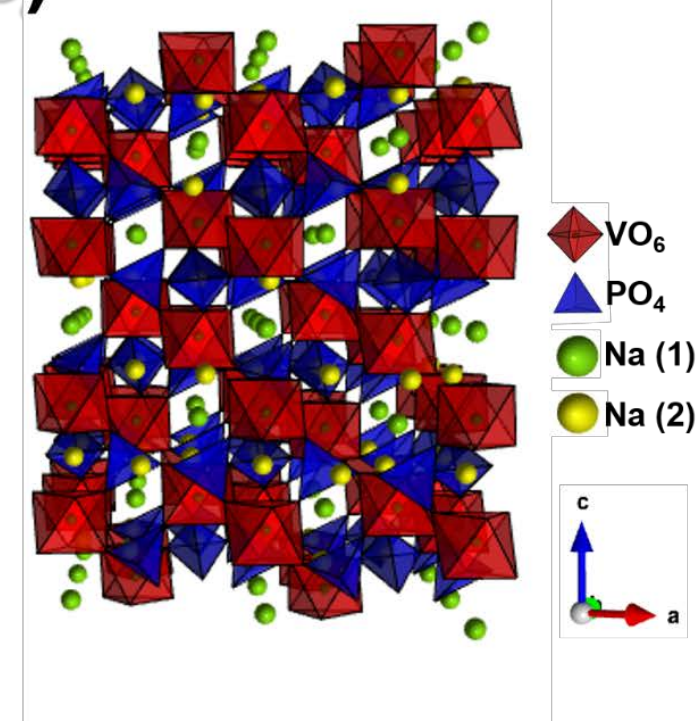

Figure 1. (a) XRD patterns of NVP-CNF-4h and NVP-CNF-6h (b) crystal structure of NVP with NASICON structure. 

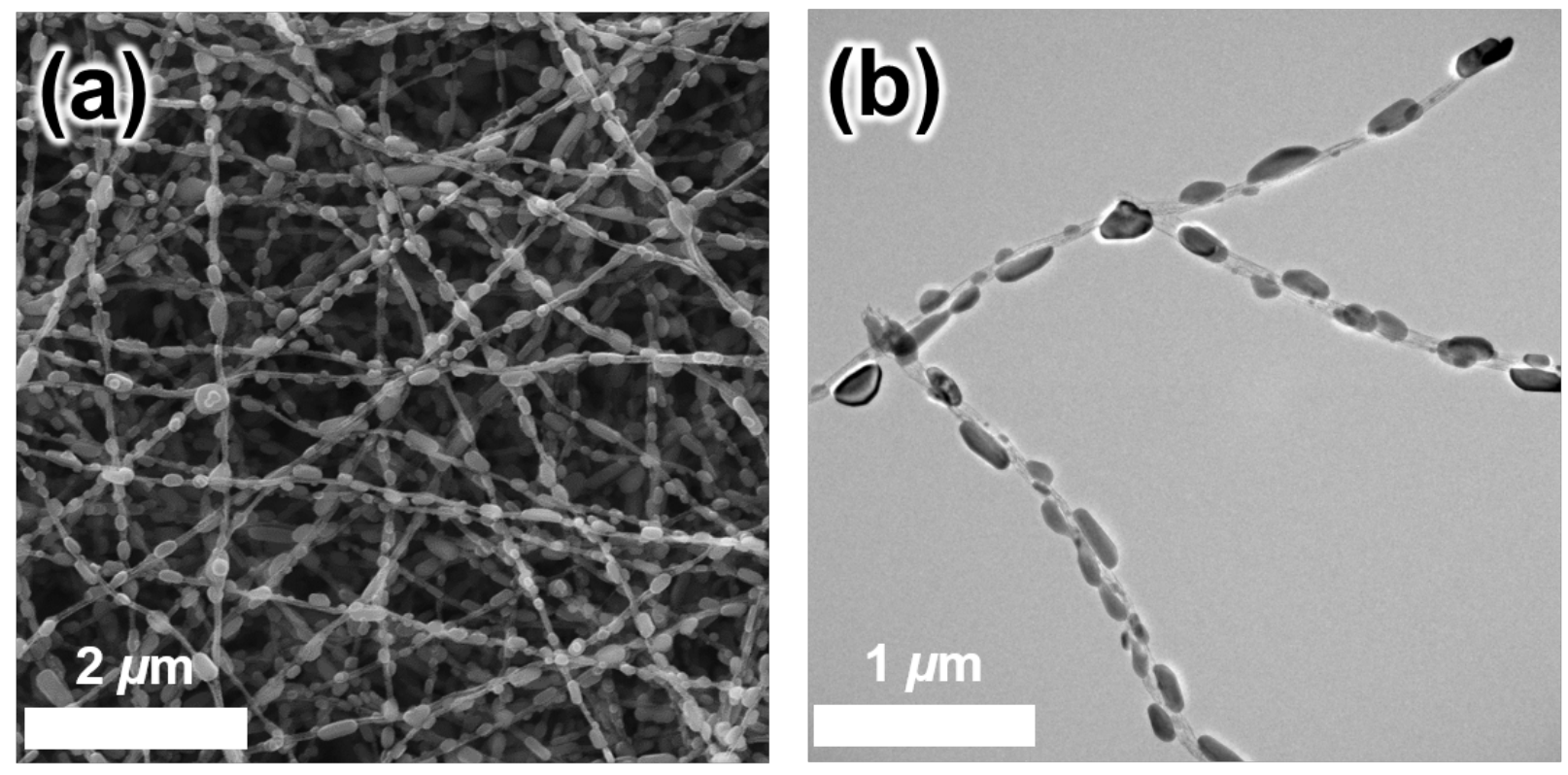

\section{(c)}

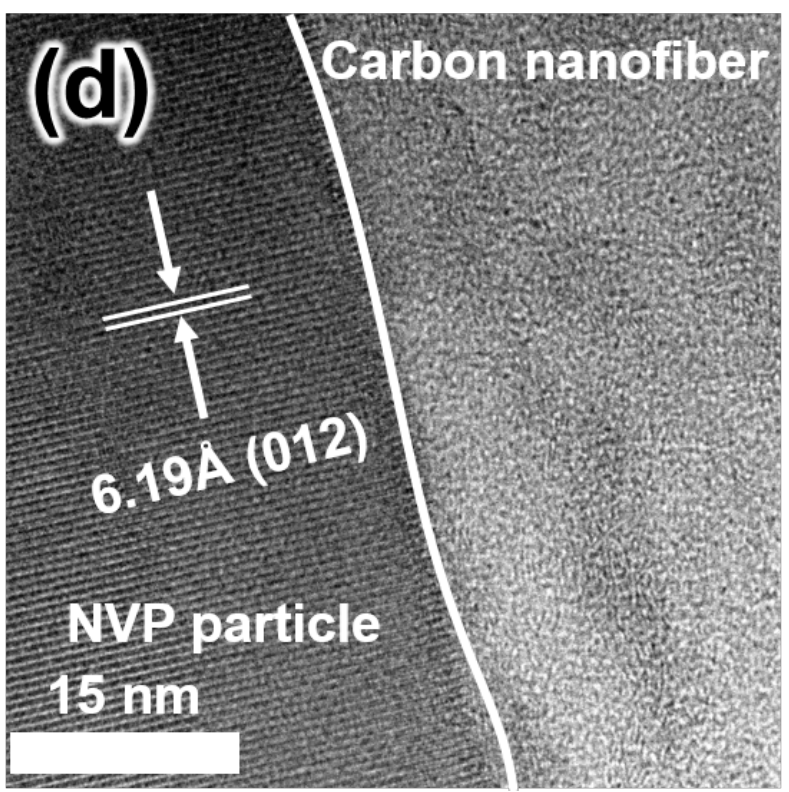

Figure 2. (a) FE-SEM, (b) TEM, and (c, d) HRTEM images of NVP-CNF composite observed from low to high magnifications. 
(a)
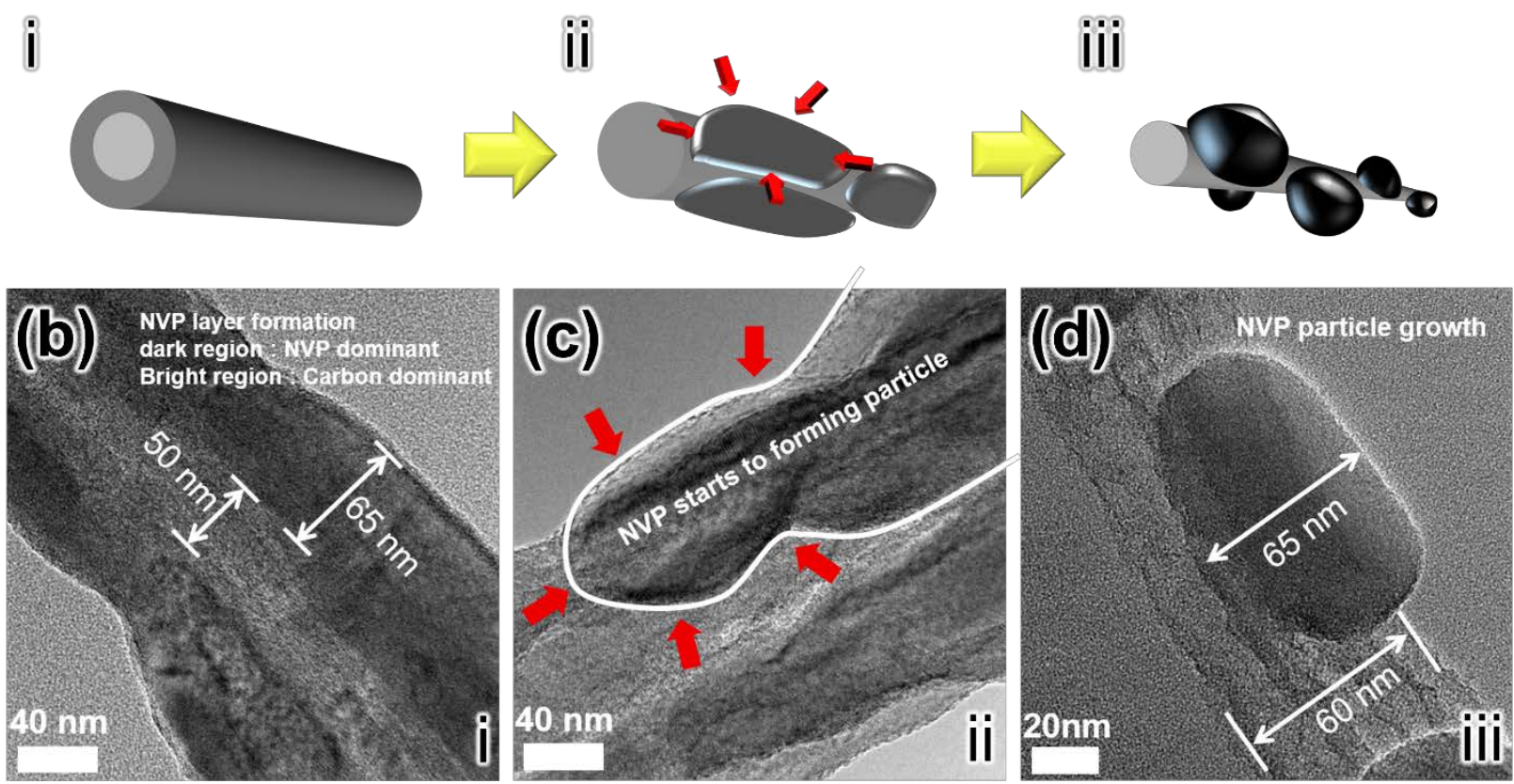

Figure 3. (a) Schematic diagram of formation process of NVP-CNF composite. TEM images of (b, c) NVP-CNF-4h observed at two different points and (d) final NVP-CNF-6h. 


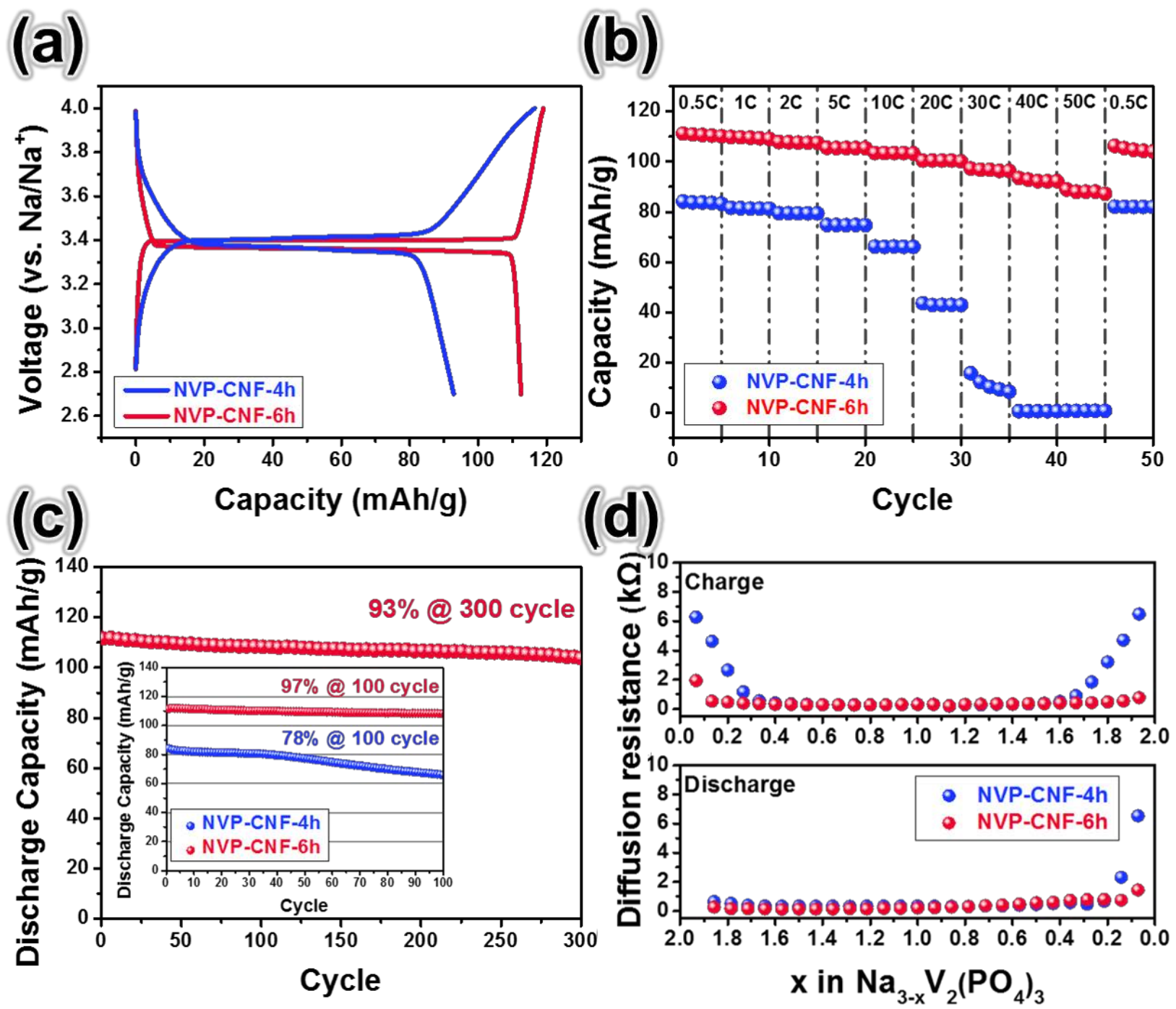

Figure 4. (a) Initial galvanostatic $(0.1 \mathrm{C})$ voltage profiles, (b) capacity retention of discharge capacities at various current rates (0.5 to 50 C-rates), (c) long-term cycling performance (1 C) up to 300 cycles and (d) diffusion resistance of NVP-CNF-4h and NVP-CNF-6h calculated from GITT curves. 


\section{EXPERIMENTAL SECTION}

\section{Preparation of NVP-CNF-4h and NVP-CNF-6h by electrospinning method.}

To prepare the electrospinning solution, stoichiometric amounts of $\mathrm{NH}_{4} \mathrm{VO}_{3}, \mathrm{NH}_{4} \mathrm{H}_{2} \mathrm{PO}_{4}$, and $\mathrm{CH}_{3} \mathrm{COONa}$ were mixed with $5 \mathrm{~mL} 14 \mathrm{wt} \%$ citric acid solution and stirred for $4 \mathrm{~h}$ at $70^{\circ} \mathrm{C}$. Following this, the prepared NVP precursor solution was added to $4 \mathrm{~mL}$ of DI water solution containing $1 \mathrm{~g}$ of poly-(vinylpyrrolidone) (PVP, Mw = 1300 000). The mixed solution then stirred for $4 \mathrm{~h}$. The mixture was immediately loaded into a plastic syringe equipped with a 27gauge needle made of plastic. The needle was connected to a high-voltage supply that generated

a DC voltage of $22.5 \mathrm{kV}$. The feeding rate for the precursor solution was $0.2 \mathrm{~mL} \mathrm{~h}^{-1}$ using a syringe pump, and the needle-to-collector distance was $7.5 \mathrm{~cm}$. The electrospinning process was conducted in air. The electrospun fiber products were annealed at $800^{\circ} \mathrm{C}$ for $4 \mathrm{~h}$ and $6 \mathrm{~h}$ in an $\mathrm{Ar}$ atmosphere at a ramp rate of $2^{\circ} \mathrm{C} \mathrm{min}^{-1}$ to yield NVP-CNF-4h and NVP-CNF-6h, respectively.

\section{Characterization}

The crystal structure of NVP-CNF-4h and NVP-CNF-6h were characterized by an X-ray diffractometer (Rigaku Ultima IV). The wavelength selected for the experiments was $\mathrm{CuK} \alpha$ radiations. The diffractometry wavelength was calibrated with an external Si standard. Data were taken over the range $10-60^{\circ}$ at a $2 \theta$ step of $0.02^{\circ}$. The morphological structure and microstructure of the NVP-CNF were observed by a field-effect scanning electron microscope (JEOL JSM6700F, operated at $15 \mathrm{kV}$ ) and a transmission electron microscope (JEOL JEM-3010, operated at $300 \mathrm{kV}$ ). The carbon content of the composite and characteristics were determined by thermogravimetric analysis (Perkin Elmer, STA6000) and Raman spectroscopy (MonoRa 750i/ELT10000), respectively. 


\section{Electrochemical measurements}

Electrodes were fabricated by mixing active material (NVP-CNF-4h and NVP-CNF-6h, respectively), acetylene black, and polyvinylidene fluoride (PVDF) at a weight ratio of 75 : 10 : 15 using $N$-methylpyrrolidone (NMP) as a solvent. The resulting slurries were pasted onto Al foils and then dried in a vacuum oven at $120^{\circ} \mathrm{C}$ for $5 \mathrm{~h}$. After drying, the electrode foils were pressed and then punched into a rectangle shape. The electrochemical properties of the prepared electrodes were evaluated using CR 2032 coin-type cells assembled in an argon-filled box. Na metal foil was used as a counter electrode, and $1 \mathrm{M} \mathrm{NaPF}_{6}$ in ethylene carbonate (EC) and diethyl carbonate (DEC) (1:1, v/v) was employed as the electrolyte. The electrochemical performance was tested by galvanostatic charge/discharge measurements conducted using a WonAtech system at room temperature in the potential range $2.7 \mathrm{~V}-4.0 \mathrm{~V}\left(\mathrm{vs} . \mathrm{Na}^{+} / \mathrm{Na}\right)$. 


\section{ASSOCIATED CONTENT}

Supporting Information Available. SEM images of electronspun nanofibers, NVP-CNF-4h and NVP-CNF-6h. Raman spectra and thermogravimetric analysis results of NVP-CNF-4h and NVPCNF-6h. Detailed TEM images of NVP-CNF-4h. STEM, TEM images and EDS line scan elemental analysis results of NVP-CNF-4h. Ex-situ XRD patterns of NVP-CNF-6h during $1^{\text {st }}$ cycle. GITT curves of NVP-CNF-4h and NVP-CNF-6h. Calculated IR-drop resistance from GITT curves during $1^{\text {st }}$ charging and discharging. This material is available free of charge via the Internet at http://pubs.acs.org.

\section{AUTHOR INFORMATION}

\section{Corresponding Author}

*dake1234@dongguk.edu (Prof. Y.-M. Kang)

\section{ACKNOWLEDGMENT}

This research was supported by (NRF-2010-C1AAA001-0029018) and the Basic Science Research Program (S-2013-A0434-00024) through the Ministry of Education, Science and Technology. 


\section{REFERENCES}

1. Aricò, A. S.; Bruce, P.; Tarascon, J.-M.; Schalkwijk, W. V. Nanostructured materials for advanced energy conversion and storage devices, Nat. Mater.2005, 4, 366-377.

2. Pasta, M.; Wessells, C. D.; Huggins, R. A.; Cui Y. A high-rate and long cycle life aqueous electrolyte battery for grid-scale energy storage. Nat. Commun. 2012, 3, 1149.

3. Wessells, C. D.; Huggins, R. A.; Cui, Y. Copper hexacyanoferrate battery electrodes with long cycle life and high power. Nat. Commun. 2011, 2, 550.

4. Kim, S.-W.; Seo, D.-H.; Ma, X.; Ceder, G.; Kang, K. Electrode Materials for Rechargeable Sodium-ion Batteries: Potential Alternatives for current Lithium-Ion Batteries. Adv. Energy Mater. 2012, 2, 710-721.

5. Palomares, V.; Serras, P.; Villauenga, I.; Hueso, K. B.; Gonzalez, J. C.; Rojo, T. Na-ion batteries, recent advances and present challenges to become low cost energy storage systems. Energy Environ. Sci. 2012, 5, 5884-5901.

6. Pan, H. L.; Hu, Y. S.; Chen, L. Q. Room-temperature stationary sodium-ion batteries for large-scale electric energy storage. Energy Environ. Sci. 2013, 6, 2338-2360.

7. Berthelot, R.; Cartlier, D.; Delmas C. Electrochemical investigation of the $\mathrm{P} 2-\mathrm{Na}_{\mathrm{x}} \mathrm{CoO}_{2}$ phase diagram. Nat. Mater. 2011, 10, 74-80.

8. Sauvage, F.; Laffont, L.; Tarascon, J. M.; Baudrin, E. Study of the Insertion/Deinsertion Mechanism of Sodium into $\mathrm{Na}_{0.44} \mathrm{MnO}_{2}$. Inorg. Chem. 2007, 46, 3289-3294. 
9. $\quad$ Cao, Y.; Xiao, L.; Wang, W.; Choi, D.; Nie, Z.; Yu, J.; Saraf, L. V.; Yang, Z.; Liu, J. Reversible Sodium Ion Insertion in Single Cyrstalline Manganese Oxide Nanowire with Long Cycle Life. Adv. Mater. 2011, 23, 3155-3160.

10. Moreau, P.; Guyomard, D.; Gaubicher, J.; Boucher, F. Structure and Stability of Sodium Intercalated Phases in Olivine $\mathrm{FePO}_{4}$. Chem. Mater. 2010, 22, 4126-4128.

11. Recham, N.; Chotard, J. N.; Dupont, L.; Djellab, K.; Armand, M.; Tarascon, J.-M. Ionothermal Synthesis of Sodium-Based Fluorophosphate Cathode Materials. $J$. Electrochem. Soc. 2009, 156, A993-A999.

12. Qian, J.; Zhou, M.; Cao, Y.; Ai, X.; Yang, H. Nanosized $\mathrm{Na}_{4} \mathrm{Fe}(\mathrm{CN})_{6} / \mathrm{C}$ Composites as a Low-Cost and High-Rate Cathode Material for Soidum-Ion Batteries. Adv. Energy Mater. 2012, 2, 410-414.

13. Lu, Y.; Wang, L.; Cheng, J.; Goodenough, J. B. Prussian blue: a new framework of electrode materials for sodium batteries. Chem. Commun. 2012, 48, 6544-6546.

14. Gaubicher, J.; Wurm, C.; Goward, G.; Masquelier, C.; Nazar, L. Rhombohedral Form of $\mathrm{Li}_{3} \mathrm{~V}_{2}\left(\mathrm{PO}_{4}\right)_{3}$ as a Cathode in Li-ion Batteries. Chem. Mater. 2000, 12, 3240-3242.

15. Jian, Z.; Zhao, L.; Pan, H.; Hu, Y.; Li, H.; Chen, W.; Chen, L. Carbon coated $\mathrm{Na}_{3} \mathrm{~V}_{2}\left(\mathrm{PO}_{4}\right)_{3}$ as novel electrode material for sodium ion batteries. Electrochem. Commun. 2012, 14, 86-89. 
16. Kang, J.; Baek, S.; Mathew, V.; Gim, J.; Song, J.; Park, H.; Chae, E.; Rai, A. K.; Kim, J. High rate performance of a $\mathrm{Na}_{3} \mathrm{~V}_{2}\left(\mathrm{PO}_{4}\right)_{3} / \mathrm{C}$ cathode prepared by pyro-synthesis for sodium-ion batteries. J. Mater. Chem. 2012, 22, 20857-20860.

17. Jung, Y. H.; Lim, C. H.; Kim, D. K. Graphene-supported $\mathrm{Na}_{3} \mathrm{~V}_{2}\left(\mathrm{PO}_{4}\right)_{3}$ as a high rate cathode material for sodium-ion batteries. J. Mater. Chem. A 2013, 1, 11350-11354.

18. Saravanan, K.; Mason, C. W.; Rudola, A.; Wong, K. H.; Balaya, P. The First Report on Excellent Cycling Stability and Superior Rate Capability of $\mathrm{Na}_{3} \mathrm{~V}_{2}\left(\mathrm{PO}_{4}\right)_{3}$ for Sodium Ion Batteries. Adv. Energy Mater. 2013, 3, 444-450.

19. Zhu, C.; Song, K.; Aken, P. A. V.; Maier, J.; Yu, Y. Carbon-coated $\mathrm{Na}_{3} \mathrm{~V}_{2}\left(\mathrm{PO}_{4}\right)_{3}$ Embedded in Porous Carbon Matrix: An ultrafast Na-Storage Cathode With the Potential of Outperforming Li Cathods. Nano Lett. 2014, 14, 2175-2180.

20. Liu, J.; Tang, K.; Song, K.; Aken, P. A. V.; Yu, Y.; Maier, J. Electrospun $\mathrm{Na}_{3} \mathrm{~V}_{2}\left(\mathrm{PO}_{4}\right)_{3} / \mathrm{C}$ nanofibers as stable cathode materials for sodium-ion batteries. Nanoscale 2014, 6, 50815086.

21. Jian, Z.; Han, W.; Lu, X.; Yang, H.; Ju. Y.-S.; Zhou. J.; Zhou, Z.; Li. J.; Chen, W.; Chen, D.; Chen. L. Superior Electrochemical Performance and Storage Mechanism of $\mathrm{Na}_{3} \mathrm{~V}_{2}\left(\mathrm{PO}_{4}\right)_{3}$ Cathode for Room-Temperature Sodium-Ion Batteries. Adv. Energy Mater. 2013, 3. 156-160.

22. Cho, Y. D.; Fey, G. T. K.; Kao, H. M. The effect of carbon coating thickness on the capacity of $\mathrm{LiFePO}_{4} / \mathrm{C}$ composite cathodes. J. Power Sources 2009, 189, 256-262. 
23. Dominiko, R.; Bele, M.; Gaberscek, M.; Remskar, M.; Hanzel, D.; Pejovnik, S.; Jamnik, J. Impact of the Carbon Coating Thickness on the Electrochemical Performance of $\mathrm{LiFePO}_{4} / \mathrm{C}$ Composites. J. Electrochem. Soc. 2005, 152, A607-A610.

24. Park, M.-S.; Needham, S. A.; Wang, G.-X.; Kang, Y.-M.; Park, J.-S.; Dou, S.-X.; Liu, H.-K. Nanostructured SnSb/Carbon Nanotube Composites Synthesized by Reductive Precipitation for Lithium-Ion Batteries. Chem. Mater. 2007, 19, 2406-2410.

25. Cushing, B. L.; Goodenough, J. B. $\mathrm{Li}_{2} \mathrm{NaV}_{2}\left(\mathrm{PO}_{4}\right)_{3}$ : A 3.7V Lithium-Insertion Cathode with the Rhombohedral NASICON Structure. J. Solid State Chem. 2001, 162, 176-181.

26. Zatovsky, I. V. NASICON-type $\mathrm{Na}_{3} \mathrm{~V}_{2}\left(\mathrm{PO}_{4}\right)_{3}$. Acta. Cryst. Sect. E 2010, 66, i12.

27. Song, W.; Ji, X.; Wu, Z.; Zhu, Y.; Yang, Y.; Chen, J.; Jing, M.; Li, F.; Banks, C. E. First exploration of Na-ion migration pathways in the NASICON structure $\mathrm{Na}_{3} \mathrm{~V}_{2}\left(\mathrm{PO}_{4}\right)_{3}$. J. Mater. Chem. A 2014, 2, 5358-5362.

28. Wang, Y.; Alsmeyer, D. C.; McCreery, R. L. Raman spectroscopy of carbon materials: structural basis of observed spectra. Chem. Mater. 1990, 2, 557-563.

29. LePolles, G.; Videau, J. J.; Olazcuaga, R.; Couzi, M. Analyse Analyse Structurale par Spectroscopie Raman et Infrarouge de Quelques Phosphates de Cuivre de Type Nasicon. J. Solid State Chem. 1996, 127, 341-349.

30. Lim, S. Y.; Kim, H.; Shakoor, R. A.; Jung, Y.; Choi, J. W. Electrochemical and Thermal Properties of NASICON Structured $\mathrm{Na}_{3} \mathrm{~V}_{2}\left(\mathrm{PO}_{4}\right)_{3}$ as a Sodium Rechargeable Battery 
Cathode: A Combined Experimental and Theoretical Study. J. Electrochem. Soc. 2012, 159. A1393-A1397. 
Synopsis (Table of Contents)

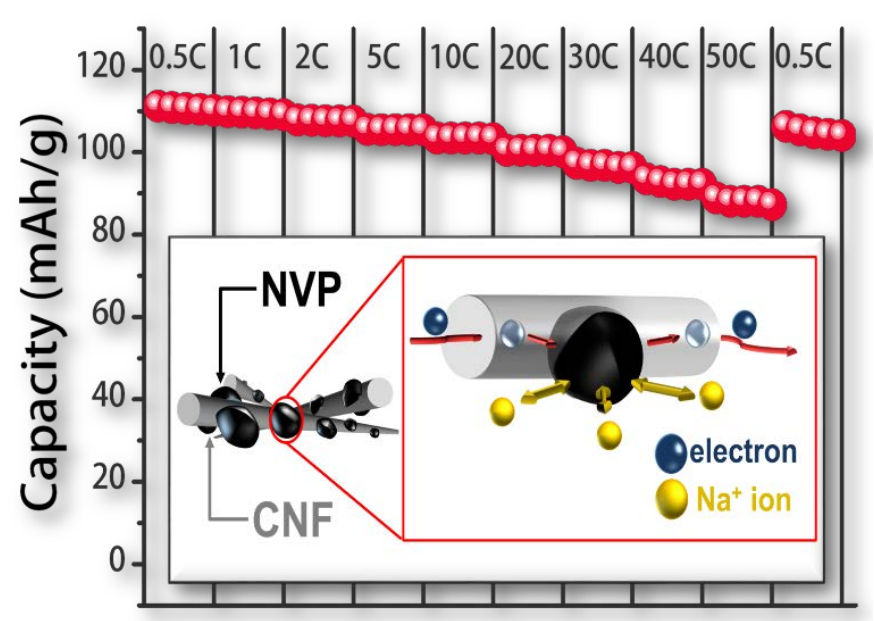

